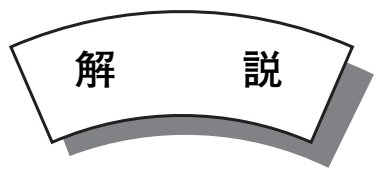

\title{
鉄鋼材料およびその溶接部組織のスマート制御の必要性に関する定量的議論 \\ Quantitative Discussion on the Necessity of SMART Control of Microstructure in Steel and Its Weld
}

\author{
寺 崎秀紀*・森口晃治** \\ Hidenori TERASAKI and Koji MORIGUCHI
}

\begin{abstract}
Key Words: Steel, CALPHAD, Weld, Enrgy Density Functional, Wide-band Gap Semiconductor, Metastable Phase
\end{abstract}
\section{1. はじめに}

鉄鋼材料を溶接した場合に形成される溶接部（溶接金属 + 溶接熱影響部) 組織は、室温でフェライト相、オーステ ナイト相、化合物または準安定相の複合組織である。各相、 化合物は溶接熱サイクル下の組織変化で形成されるが。そ の制御の難しさは、特に各相の安定性を“ギブスの自由エ ネルギー”による場で眺めると理解しやすい。その“エネ ルギー場の浅さ”は特筆すべきものであり、その組織制御 の達成にはスマート制御の確立 (“やれしまっている”から、 理解に基づく制御へ) が必須と考える。

本稿の目的はその“自由エネルギー場の浅さ”、を定量的 に示し、溶接部を含む鉄鋼材料の組織制御技術を、制御工 ネルギー論的な観点から眺める機会を供することである。

\section{2. 正則溶体モデル}

まずは、釈迦に説法ではあるが、ギブスの自由エネルギー を以下のように導入する。

温度 $T$ 、圧力 $P$ が一定に保たれている系を考える。系に は圧力が作用しているので、カノニカル分布をとる系が体 積 $V$ を持つ確率 $P(V)$ は次式となる ${ }^{1)}$ :

$P(V) \propto Z(V) e^{-P V / k_{B} T}$

ここで、 $Z(V)$ は、系が体積 $V$ を持つときの分配関数（量子 状態に対応した確率の総和)、 $k_{B}$ はボルツマン定数である。 自由エネルギーを

$-k_{B} T \log Z(V)=F(V)=E-T S$

導入すると（S はエネルギーEに扔けるエントロピー）、
$P(V) \propto \exp \left[-\frac{1}{k_{B} T}\{E-T S+P V\}\right]$

となり、等温・等圧下で、実現確率最大の体積をトラック

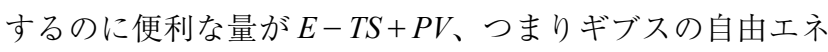
ルギー（以下 $G$ ) であることがわかる。

本稿の最初の作業は、計算プログラム作成に例えるなら ば、濃度、温度を引数として、Gを返す関数を作成するこ とである。オーステナイト相拉よびフェライト相の $G$ を記 述する前に、液相の $G$ を解説しょう。これにより、オース テナイト相、フェライト相の $G$ を記述するのに使用される モデルの一般性と特殊性が理解できるためである。

液相の $G$ を記述するのに使用するモデルは正則溶体モデ ルである。まずはいきなり答えを示すと：

$$
\begin{aligned}
G^{\text {liquid }}= & x_{F e}{ }^{0} G_{F e}^{\text {liquid }}+x_{C}{ }^{0} G_{C}^{\text {liquid }} \\
& +R T\left\{x_{F e} \log \left(x_{F e}\right)+x_{C} \log \left(x_{C}\right)\right\} \\
& +x_{F e} x_{C} L_{F e \cdot C}^{\text {liquid }}
\end{aligned}
$$

となる。ここで、 $x_{F e} 、 x_{C}$ は鉄㧍よび炭素の組成 (モル分率)、 ${ }^{0} G_{X}$ はX $\mathrm{X}$ 結晶 1 モルのギブスの自由エネルギー、 $L_{F e: C}^{\text {liquid }}$ は相 互作用パラメータである。

単純に $x_{F e}{ }^{0} G_{F e}^{\text {liquid }}+x_{C}{ }^{0} G_{C}^{\text {liquid }}$ とならないところがポイント で、溶体形成の効果、つまり混合によるエントロピー $\left(R T\left\{x_{F e}\right.\right.$ $\left.\left.\log \left(x_{F e}\right)+x_{C} \log \left(x_{C}\right)\right\}\right)$ とエンタルピー $\left(x_{F e} x_{C} L_{F e \cdot C}^{\text {liquid }}\right)$ の変化 の効果が表現されている。後述する、やや異なるモデルで 表現するオーステナイト相、フェライト相のギブスの自由 エネルギーでも、大きくはこのような解釈が成り立つため、 以下に(4)式を導出してみよう。

$N_{F e}$ 個の鉄原子、 $N_{C}$ 個の炭素原子を $\mathrm{N}=N_{F e}+N_{C}$ 個 の格子点にランダム配置すると、配置の場合の数は

*大阪大学接合科学研究所 ( $\overline{7}$ 567-0047 大阪府茨木市美穂ヶ丘 11-1)

Joining and Welding Research Institute, Osaka Universit (11-1 Mihogaoka, ibaraki, Osaka, 567-0047 Japan)

$* *$ 新日鐵住金(侏) 技術開発本部 鉄鋼研究所（广 660-0891 兵庫県尼崎市扶桑町 1-8）

Steel Research Laboratories, Technical Research \& Development Bureau, Nippon Steel and Sumitomo Metal Corporation

(1-8 Fuso-cho, Amagasaki, Hyogo, 660-0891 Japan) 
スマートプロセス学会誌

$W_{\text {配置 }}^{F e-C}=\frac{N !}{N_{F e} ! N_{C} !}$ となり、これをエントロピーの定義に代入

して、

$S_{\text {混合 }}=k_{B} \log \left(\frac{N !}{N_{F e} ! N_{C} !}\right)$

を得る。階乗関数の近似を与える Stirling's Approximation $(\log N ! \approx N \log N-N)$ 、および両原子の総量を 1 モルとする と $\left(N=6.022 \times 10^{23} \mathrm{~mol}^{-1}\right) 、\left(S_{\text {混合 }}=-R\left(x_{F e} \log \left(x_{F e}\right)+x_{C} \log \left(x_{C}\right)\right)\right.$ を得る。 A、B 原子の量子状態の総数をそれぞれ、 $W_{A} 、 W_{B}$ とすると量子状態の総数は $W_{A}^{N_{A}} \cdot W_{B}^{N_{B}} \cdot W_{\text {配置 }}^{F}$ となるが、 $W_{A}^{N_{A}} \cdot W_{B}^{N_{B}}$ をエントロピーの定義に代入した部分は、(4) 式 第 $1 、 2$ 項を構成する。

次に混合エンタルピー項であるが、原子対の結合エネル ギーの総和を求める。各原子対の数を $P$ 、原子対一対あた りの結合エネルギーを $\varepsilon$ とするとエンタルピー $H$ の次式を 得る ${ }^{2)}$ 。

$\mathrm{H}=\varepsilon_{\mathrm{FeFe}} \cdot \mathrm{P}_{\mathrm{FeFe}}+\varepsilon_{C C} \cdot \mathrm{P}_{C C}+\varepsilon_{\mathrm{FeC}} \cdot \mathrm{P}_{\mathrm{FeC}}$

1 つの格子点から最も近い原子の数を $Z$ とすると、 $P_{F e F e}$ 、 $P_{C C} 、 P_{F e C}$ はそれぞれ $(Z N / 2) x_{F e}^{2} 、(Z N / 2) x_{C}^{2} 、 Z N x_{F e} x_{C}$ となる ので（同種原子の場合は重複を考慮して $1 / 2$ )、次式を得る：

$H=\frac{Z N}{2} \varepsilon_{F e F e} \cdot x_{F e}+\frac{Z N}{2} \varepsilon_{C C} \cdot x_{C}$

$+Z N\left(\varepsilon_{F e C}-\frac{\varepsilon_{F e F e}+\varepsilon_{C C}}{2}\right) x_{F e} x_{C}$

$={ }^{0} H_{F e} \cdot x_{F e}+{ }^{0} H_{C} \cdot x_{C}+L_{F e C}^{\text {liquid }} x_{F e} x_{C}$

(ちなみに、(7) 式最初の 2 項は (4) 式第 $1 、 2$ 項を構成する。) 前述の目的（濃度、温度を引数として、Gを返す関数 を作成）を達成するにあたって、あとは、式 (4) 中の、 ${ }^{0} G_{F e}^{\text {liquid }}{ }^{0} G_{C}^{\text {liquid }} 、 L_{F e: C}^{\text {liquid }}$ を求めるだけであるが、これらは参 考文献 3)において、温度のべき乗を引数とする関数として 与えられており、簡単に入手できる (Appendix 1 を参照)。 計算例はオーステナイト相、フェライト相のギブスの自由 エネルギーを与える関数を説明した後に、 $\mathrm{Fe}-\mathrm{C}$ 二元系包晶 温度における 3 相の自由エネルギーを描画して示す。

\section{3. 副格子モデル}

次にオーステナイト相を対象に同様の関数を求めるが、 オーステナイト相は侵入型溶体であり、炭素原子の配置に 特別の制約がある。そのため、鉄原子が配置される場所と、 炭素および空孔が配置される格子を、区別して表現できる 副格子モデルを使用する（Fig. 1）。

まずはより一般性をもって、複合化合物 $(A, B)_{m}(C, D)_{n}$ を 仮想した、副格子モデルの $G$ は、 $y_{A} 、 y_{B} 、 y_{C} 、 y_{D}$ は各元素
第 2 巻 第 3 号（2013 年 5 月）

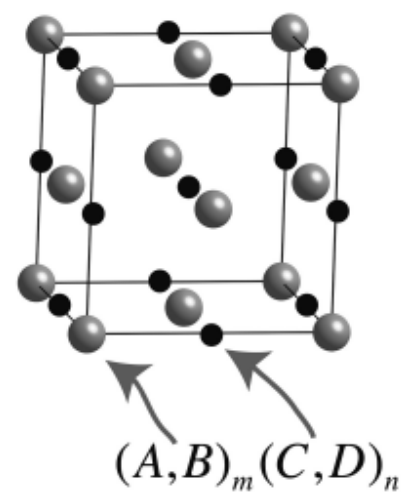

Fig. 1 Sub-lattice model

がそれぞれ属する格子における分率で以下の式で表され る:

$$
\begin{aligned}
G & =G_{A_{m} C_{n}} y_{A} y_{C}+G_{B_{m} C_{n}} y_{B} y_{C}+G_{A_{m} D_{n}} y_{A} y_{D}+G_{B_{m} D_{n}} y_{B} y_{D} \\
& +m\left(L_{A B}^{C} y_{C}+L_{A B}^{D} y_{D}\right) y_{A} y_{B}+n\left(L_{C D}^{A} y_{A}+L_{C D}^{B} y_{B}\right) y_{C} y_{D} \\
& +R T\left[m\left\{y_{A} \log \left(y_{A}\right)+y_{B} \log \left(y_{B}\right)\right\}+n\left\{y_{C} \log \left(y_{C}\right)+y_{D} \log \left(y_{D}\right)\right\}\right]
\end{aligned}
$$

各項の意味は正則溶体モデルの理解から類推すれば、容 易であろう。 Fe-C二元系のオーステナイト相の場合、 A は 鉄原子、Bは無し（鉄がすべての格子を占める）、C を炭素、 D を空孔となり、2つの FCC 格子にそれぞれ配置するので、 $m=n=1$ となる。よって、オーステナイト相の $G$ は：

$G=G_{F e C}^{\gamma} y_{C}+G_{F e v a}^{\gamma} y_{v a}+L_{C v a}^{F e} y_{C} y_{v a}$

$+R T\left(y_{C} \log y_{C}+y_{v a} \log y_{v a}\right)$

となる。 $G_{\mathrm{FeC}}^{\gamma} 、 G_{\mathrm{Feva}}^{\gamma} 、 L_{\mathrm{Cva}}^{\gamma \mathrm{Fe}}$ は、式 (7) と同様に、温度のべ き乗を引数とする関数として、参考文献 3)より得られる (Appendix 2 を参照)。今までの導出では鉄原子が 1 モルと なっているので、例えば、(4) 式と比較する場合に注意が必 要 $\left(x_{F e}\right.$ を乗する $)$ となる。さらに以下の $y_{C}$ と濃度関係を 考慮すると (9) 式が使いやすくなる：

$x_{C}=\frac{y_{C}}{1+y_{C}}$

さていよいよフェライトである。使用するモデルはオー ステナイト相と同じであるが、結晶構造の違いにより、仮 想複合化合物のモル比が異なり、 $m=1 、 n=3$ となる。よっ て、Gは：

$G=G_{F e C}^{\alpha} y_{C}+G_{F e v a}^{\alpha} y_{v a}(1-y c)$

$+3\left(L_{C v a}^{\alpha F e}\right) y_{C}\left(1-y_{C}\right)$

$+3 R T\left\{y_{C} \log y_{C}+\left(1-y_{C}\right) \log \left(1-y_{C}\right)\right\}$ 


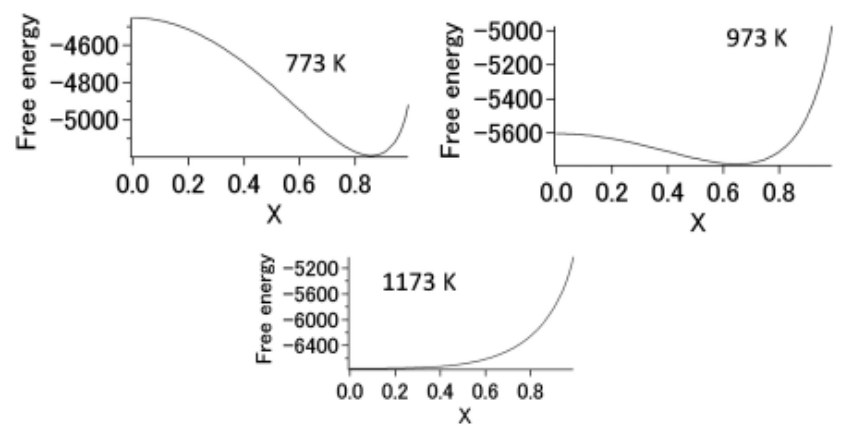

Fig. 2 Stability of spins as a function of ferromagnetic parameter.

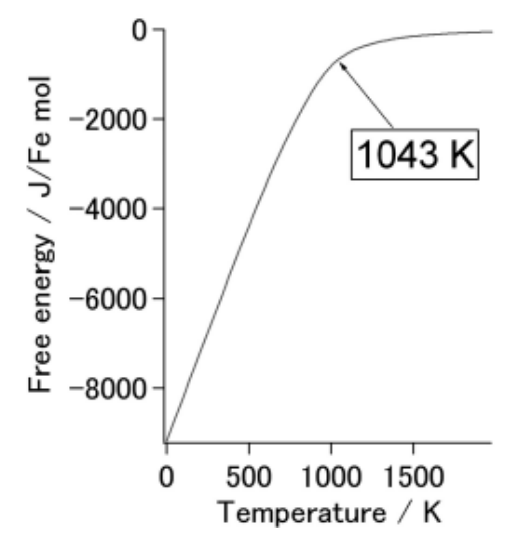

Fig. 3 Gmag term

と整理できるが(Appendix 3)、これだけでは不十分である。 磁気スピンの揃いやすさを表す強磁性パラメータをX $(0$ では磁気スピンはランダム配置、1では同じ方向に配置さ れる）として、正則溶体モデルと同じ考え方で、結合エネ ルギーの代わりにスピン間の引力を考元、スピンの配置に より生じるエントロピーを考慮して自由エネルギーにより スピン配列に関する安定性を評価すると ${ }^{2,4)}$ 、Fig. 2 の結果 を得る。

$773 \mathrm{~K}$ では、スピンが揃ったほうが安定であり、温度が 上昇するにつれ、スピン配置のランダムさが増し、1173で は、ランダム配置が安定となることがわかる。この性質は 磁性相互作用としてギブス自由エネルギーに寄与すること が知られており、それを反映した $G_{\text {mag }}$ 項を (11) 式に加える。 Bcc 鉄の場合、スピン配置のランダム性の臨界值は $1043 \mathrm{~K}$

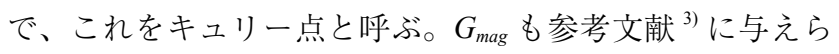
れおり (Appendix 3)、温度を横軸として、描画すると Fig. 3 のようになる。

以上、(4) 式、(9) 式、(11) 式 $+G_{\text {mag }}$ 項を使って描画した、 包晶温度 (三相同時に確認できるため) での自由エネルギー 曲線を Fig. 4 に示す。

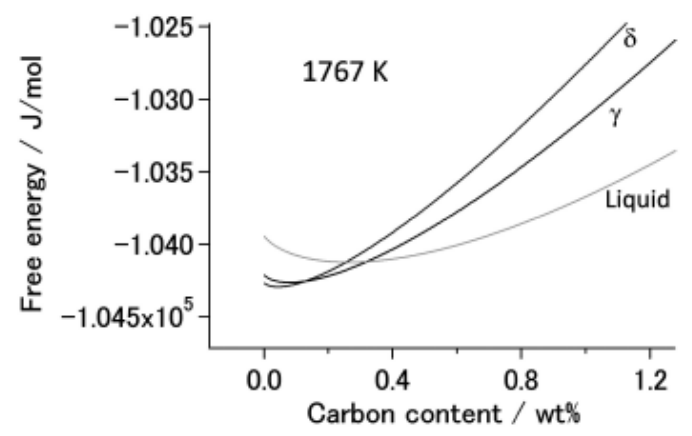

Fig. 4 Calculated free energy at peritectic point.

\section{4. エネルギー沉関数としての応用}

近年、エネルギー密度場（汎関数）を定義し、計算領域で 総和をとり、その総和の変分項を、定義した相場の時間発 展式（停留值探索）としたものを基本式とする、フェイズ フィールドシミュレーション法を活用した研究が盛んであ る5,6。エネルギー密度としてギブスの自由エネルギーと二 相間の界面エネルギーを考慮した場合、秩序変数 $\phi$ （フエ ライトを 0、オーステナイトを1で表し、連続的に変化す る定義量）の関数として、エネルギー密度場は、現象論的 に以下のように定義できる ${ }^{5,6)}$ :

$G_{m}=(1-p(\phi)) G_{m}^{\alpha}+p(\phi) G_{m}^{\gamma}+g(\phi) W$

$p(\phi)=\phi^{3}\left(10-15 \phi+6 \phi^{2}\right)$

$g(\phi)=\phi^{2}(1-\phi)^{2}$

ここで、 $W$ は相を隔てる界面エネルギーに相当する量であ る。

式(12)の振る舞いを見るため、(9) 式、(11) 式 $+G_{\text {mag }}$ を 使用して、 $\mathrm{T}=1050 \mathrm{~K}$ に扔ける二相領域（炭素組成： $\mathrm{x}_{\mathrm{C}}{ }^{0}=1.0$ at.\%、Fig. 5(a)の赤点）に扔けるバルク自由エネルギー、

$G_{b u l k}=\left(1-\phi_{\nu}\right) G_{m}{ }^{\alpha}+\phi_{\gamma} G_{m}{ }^{\gamma}$

を、平衡状態を基準にしてプロットした等高線を Fig. 5(b) に示す。ここで、 $\phi_{y}$ はオーステナイト相の相分率で、 $x_{y}(C)$ は炭素濃度である。相分率や炭素組成の広い領域に渡り、 平衡状態からの自由エネルギーの差は、高々、 $\mathrm{meV} / \mathrm{atom} L$ かないことが分かる $(1 \mathrm{meV} /$ atom $\approx 96 \mathrm{~J} / \mathrm{mol}) 。$

Fig. 5 のエネルギー単位は meV/atom としているが、こ のエネルギー差がどの程度なのかを、種々の材料系の制御 エネルギーと比較してみるのは興味深いだろう。例えば、 ナノテクノロジーを代表する IV 族あるいは III-V 族のワ イドギャップ半導体では、しばしば、積層多形 (Polytype) の同素体構造が出現し、その結晶構造制御が半導体特性制 御に重要となっている。Fig. 6 にいくつかのワイドギャッ プ半導体における積層多形が存在するエネルギー範囲を示 す ${ }^{8)}$ 。横軸は、積層多形を分類する Hexagonality（0 が $3 \mathrm{C}$ 

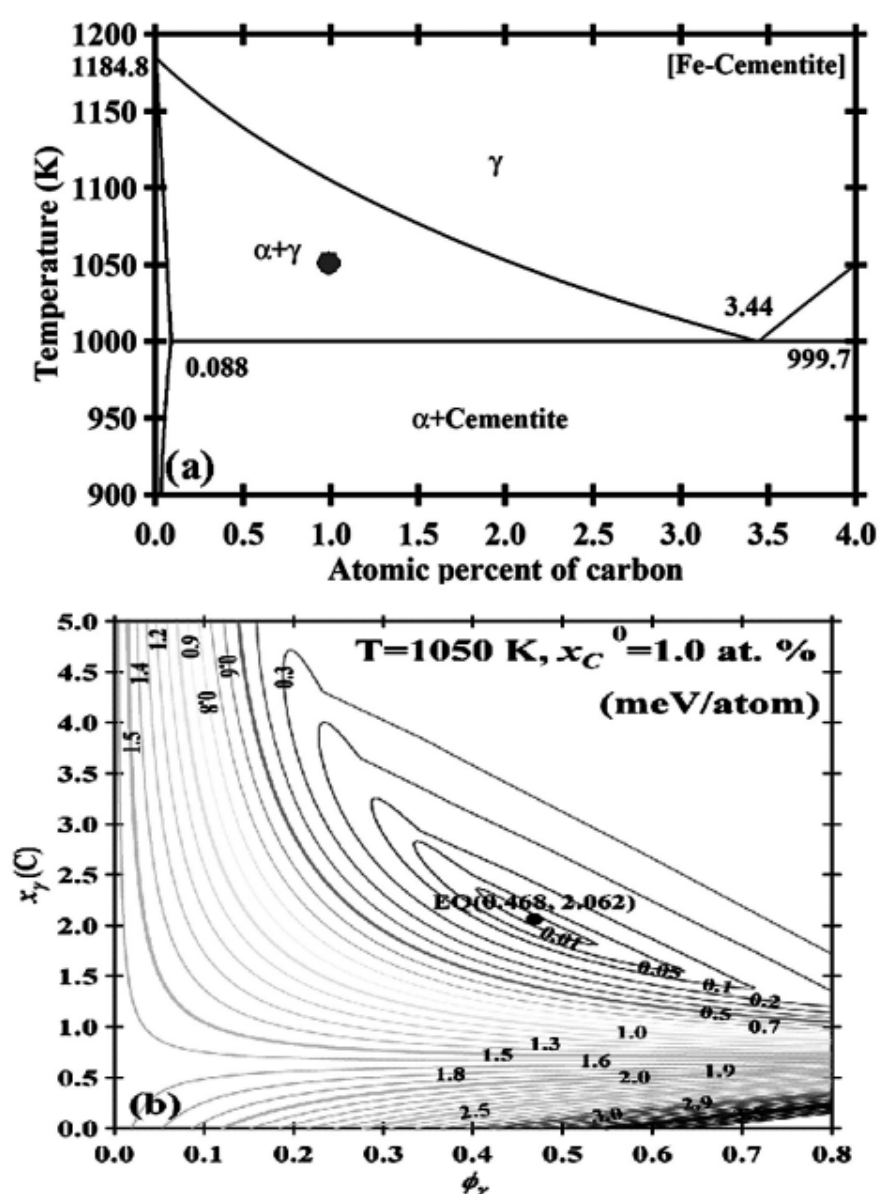

Fig. 5 (a) Phase-diagram for Fe-C system calculated using the thermodynamic assignment in Ref. [3] and (b) Contour map of $G_{b u l k}$ as a function of $\phi_{\gamma}$ (the $\gamma$-phase fraction) and $x_{\gamma}(C)$ (the carbon concentration in $\gamma$-phase ). The bulk free energy increments (in $\mathrm{meV} /$ atom) from the equilibrium state [ $\mathrm{in}(\mathrm{b})]$ for $\mathrm{T}=1050 \mathrm{~K}$ and $x_{c}{ }^{0}=1.0$ at.\% ( $\mathrm{in}$ (a)) are plotted.

構造、 1 が $2 \mathrm{H}$ 構造に相当する）と呼ばれる変数である。 $\mathrm{SiC}$ は、同素体間のエネルギー縮退が比較的大きい系とな るが、他のワイドギャップ半導体はFig. 5 に示すエネルギー 差に比べれば、一桁程度制御エネルギー（同素体の存在範 囲）が大きいことが分かる。鉄鋼材料の組織制御技術が、 制御エネルギー論的な観点から眺めると、如何に超ハイテ クであるかを示す一例である。

安定相の差ですら上述の程度である鉄鋼材料であるが、 産業上重要な組織である、マルテンサイトは準安定相とし て出現する。最初に述べた、溶接部組織の形成においては、 速い冷却速度の熱サイクルが主となるため、マルテンサイ 卜形成頻度は高く、その組織制御の困難さを定量的に理解 していただけると思う。この準安定相の生成を考慮できる、 エネルギー密度場はどのように定義すればよいのであろう か。Fig. 5 の場において準安定相を定義することはできな い。一つの回答が Bouvlle ${ }^{7}$ の仕事であろう。Bouville は温 度と溶質濃度に加えて、偏差ひずみの次元を導入すること で、準安定相であるマルテンサイトを含む、エネルギー場
を定義し (Fig. 7)、拡散・無拡散の両変態を考慮できるモ デルを提案し、鉄鋼材料の TTT 線図のシミュレーションを 行った。二つの変態機構の相互作用によりベイナイト組織 が形成されることを示唆する結果も得られている。これら 結果は準安定相を含む組織の制御には、材料の弾性定数と 組織変化の関係や、変態ひずみの緩和挙動の理解が重要で あることを示唆している。

\section{5. おわりに}

$\mathrm{Fe}-\mathrm{C}$ 系熱力学モデルを解説し、安定相間の“自由エネル ギー場の浅さ”を定量的に示した。さらに、工業的に重要 な準安定相制御に必要な知見ついて述べた。本稿により、 鉄鋼材料やその溶接部組織の組織制御が、制御エネルギー 論的な観点から眺めると、超ハイテクであること（実際の 材料はさらに多元系である!）を伝えられたら幸いである。 本特集号では、つづいて、組織変化の素過程となる結晶材 料の相安定性と弾性定数との相関に関する理論、変態ひず み緩和挙動と形成組織の関係を理解するのに必要な、鉄鋼 


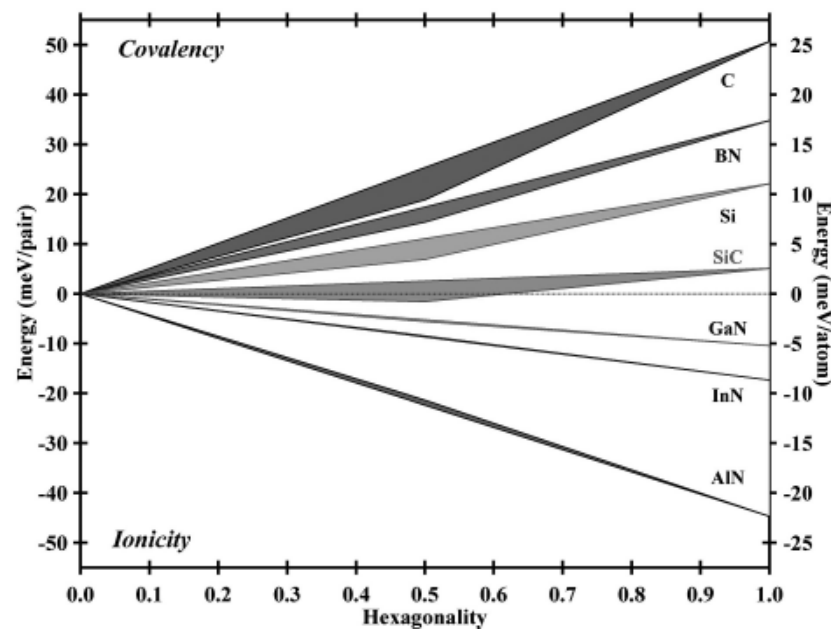

Fig. 6 Polytype energetic map for some wide-band gap semiconductors. (from Ref. 8)
材料組織に関する最新の結晶学的知見、形成されるミクロ 組織とマクロな機械的性質の関係が解説される。

\section{引用文献}

1) 統計力学、長岡洋介、岩波書店、1994, 87.

2) ミクロ組織の熱力学、西澤泰二、日本金属学会、2005, 55

3) P. Gustafson, Scandinavian Journal of Metallurgy, 14 (1985), 259267.

4) Computatonal Physics, S. Koonin, D. C. Meredith, Addison Wesley, 1990, 215.

5) R. Kobayashi, Physica D, 63 (1993), 410.

6) I. Loginova, J. Odqvist, G. Amberg and J. Agren, Acta Mater., 51 (2003), 1327-1339.

7) M. Bouville and R. Ahluwalia, Phys. Rev. Lett., 97 (2006), 055701.

8) K. Moriguchi, K. Kamei, K. Kusunoki, N. Yashiro and N. Okada, J. Mater. Res. 28, 7 (2013).

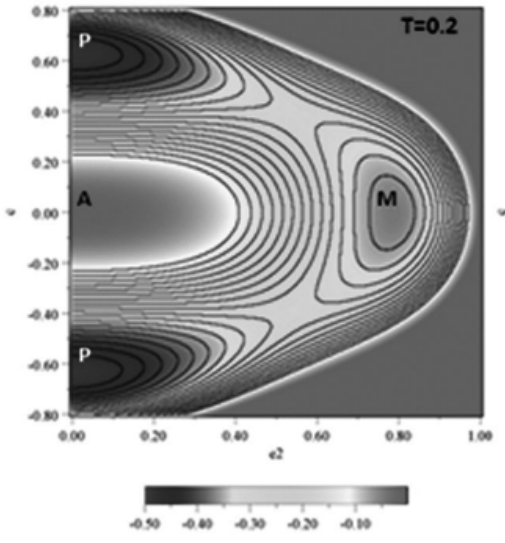

$\underline{T}<\underline{\underline{M}}$

A: unstable

P: ground

M:

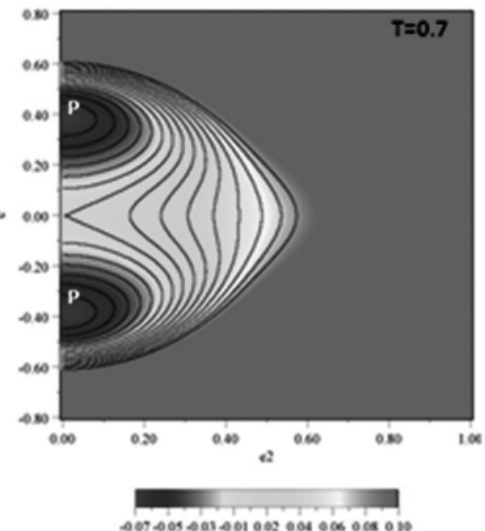

$$
\underline{T}_{\underline{M}} \leq T<T_{\underline{p}}
$$

\section{A: unstable \\ P: ground}

M: unstable

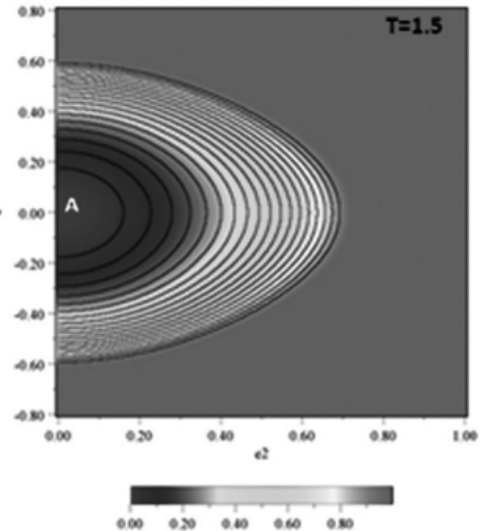

$\underline{T}>T_{\underline{p}}$

A: ground

P: unstable

M: unstable

Fig. 7 Potential proposed by Bouville and Rajeev ${ }^{7)}$. 


\section{$<$ Appendix $1>$}

$(298.15 \leq \mathrm{T} \leq 1811)$

$$
\begin{aligned}
{ }^{0} G_{F e}^{\text {liquid }}= & 13265.0+117.57557 \times T \\
& -3.6751551 E-21 \times T^{7}-23.5143 \times T \times \ln (T) \\
& -0.00439752 \times T^{2}-5.89269 E-8 \times T^{3}+77358.5 \times T^{-1}
\end{aligned}
$$

Aeq (1)

$(1811 \leq \mathrm{T} \leq 6000)$

${ }^{0} G_{F e}^{\text {liquid }}=10839.7+291.302 \times \mathrm{T}-46.0 \times \mathrm{T} \times \ln (\mathrm{T})$

Aeq (2)

以上単位は $[\mathrm{J} / \mathrm{Fe} \mathrm{mol}]$ となる。

$$
\begin{aligned}
&(298.15 \leq \mathrm{T} \leq 6000) \\
&{ }^{0} G_{F e}^{\text {liquid }}= 100000+146.1 \times T-24.3 \times T \times \ln (T) \\
&-4.723 E-4 \times T^{2}+2562000 \times T^{-1} \\
&-2.643 E 8 \times T^{-2}+1.2 E 10 \times T^{-3}
\end{aligned}
$$

Aeq (3)

単位は [ [J/ C mol] となる。

$$
\begin{aligned}
& \mathrm{VL} 0=-124320.0+28.5 \times \mathrm{T} \\
& \mathrm{VL} 1=19300.0 \\
& \mathrm{VL} 2=49260.0-19.0 \times \mathrm{T} \\
& L_{F e: C}^{\text {liquid }}=\mathrm{VL} 0+\mathrm{VL} 1 \times\left(x_{C}-x_{F e}\right)+\mathrm{VL} 2 \times\left(x_{C}-x_{F e}\right)^{2}
\end{aligned}
$$

Aeq (4)

\section{$<$ Appendix 2>}

$$
\begin{aligned}
& (298.15 \leq \mathrm{T} \leq 1811) \\
& \begin{aligned}
G_{\text {Feva }}^{\gamma}=- & 237.57+132.416 \times T-24.6643 \times T \times \ln (T) \\
\quad & 0.00375752 \times T^{2}-5.89269 E-8 \times T^{3}+77358.5 \times T^{-1}
\end{aligned}
\end{aligned}
$$

Aeq (5)

$$
\begin{aligned}
&(1811 \leq \mathrm{T} \leq 6000) \\
& G_{\text {Feva }}^{\gamma}=-27098.266+300.25256 \times T \\
&-46.0 \times T \times \ln (T)+2.78854 E 31 \times T^{-9}
\end{aligned}
$$

Aeq (6)

以上単位は $[\mathrm{J} / \mathrm{Fe} \mathrm{mol}]$ となる。

$$
\begin{aligned}
G_{F e C}^{\alpha}=G_{F e v a} & (T)+77207.0-15.877 \times T-17369.0+170.73 \times T \\
& -24.3 \times T \times \ln (T)-4.723 E-4 \times T^{2}+2562600 \times T^{-1} \\
& -2.643 E 8 \times T^{-2}+1.2 E 10 \times T^{-3}
\end{aligned}
$$

単位は [ J/ C mol] となる。

$$
L_{C v a}^{\gamma F e}=-34671.0[\mathrm{~J} / \mathrm{mol}]
$$

\section{$<$ Appendix 3>}

$$
\begin{aligned}
&(298.15 \leq \mathrm{T} \leq 1811) \\
& G_{\text {Feva }}^{\alpha}= 1224.83+124.134 \times T-23.5143 \times T \times \ln (T)-0.00439752 \times T^{2} \\
&-5.89269 E-8 \times T^{3}+77358.5 \times T^{-1}
\end{aligned}
$$

Aeq (9)

$$
\begin{aligned}
&(1811 \leq \mathrm{T} \leq 6000) \\
& G_{F e v a}^{\alpha}=-25384.451+299.31255 \times T \\
& \quad-46.0 \times T \times \ln (T)+2.2960305 E 31 \times T^{-9}
\end{aligned}
$$

Aeq (10)

以上単位は $[\mathrm{J} / \mathrm{Fe} \mathrm{mol}]$ となる。

$$
\begin{aligned}
G_{\text {FeC }}^{\alpha}=G_{\text {Feva }}^{\alpha}(T)+ & 322050+75.667 \times \mathrm{T}+3.0 \times\{-17369.0+170.73 \times T \\
& -24.3 \times T \times \ln (T)-4.723 E-4 \times T^{2}+2562600 \times T^{-1} \\
& \left.-2.643 E 8 \times T^{-2}+1.2 E 10 \times T^{-3}\right\}
\end{aligned}
$$

単位は [ [J/ C mol] となる。

$3 L_{\mathrm{Cva}}^{\alpha F e}=-190 \times T[\mathrm{~J} / \mathrm{mol}]$

さらに

$\tau=T / T_{C}$

ここで、 $T_{C}$ はキュリー点。

$(\tau>1)$

$G_{\text {mag }}=-6507.7 \times \tau^{-4} / 10.0+\tau^{-14} / 315.0+\tau^{-24} / 1500.0$

$(\tau<1)$

$G_{\text {mag }}=-9180.5+9.723 \times T-9309.8 \times \tau^{4} / 6.0$ $+\tau^{10} / 135.0+\tau^{6} / 600.0$

Aeq (13)

$$
\text { 以上単位は [J/ Fe mol] となる。 }
$$

